\title{
Morphological Modification and Analysis of ZnO Nanorods and Their Optical Properties and Polarization
}

\author{
Nandang Mufti $\left(\mathbb{D},{ }^{1,2}\right.$ Siti Maryam, ${ }^{1}$ Anggun A. Fibriyanti $\left(\mathbb{D},{ }^{1}\right.$ Robi Kurniawan $\left(\mathbb{D},{ }^{1}\right.$ \\ Abdulloh Fuad $\mathbb{D}^{1,2}$ Ahmad Taufiq, ${ }^{1,2}$ and Sunaryono $\mathbb{D}^{1,2}$ \\ ${ }^{1}$ Department of Physics, Faculty of Mathematics and Natural Sciences, Universitas Negeri Malang, Jl. Semarang 5, Malang, \\ 65145 East Java, Indonesia \\ ${ }^{2}$ Centre of Advanced Materials for Renewable Energy, Universitas Negeri Malang, Jl. Semarang 5, Malang, 65145 East Java, Indonesia
}

Correspondence should be addressed to Nandang Mufti; nandang.mufti.fmipa@um.ac.id

Received 17 May 2018; Revised 8 August 2018; Accepted 28 August 2018; Published 5 November 2018

Academic Editor: Francesco Ruffino

Copyright ( 2018 Nandang Mufti et al. This is an open access article distributed under the Creative Commons Attribution License, which permits unrestricted use, distribution, and reproduction in any medium, provided the original work is properly cited.

\begin{abstract}
We report on the effect of the morphological modification on optical properties and polarization of $\mathrm{ZnO}$ nanorods (NR). Here, the morphology and structure of the $\mathrm{ZnO} \mathrm{NR}$ were modified by introducing different annealing temperatures. The increase of length and diameter and change in density of the $\mathrm{ZnO} \mathrm{NR}$ were clearly observed by increasing the annealing temperature. We found that the samples show different oxygen vacancy $\left(\mathrm{V}_{\mathrm{O}}\right)$ and zinc interstitial $\left(\mathrm{Zn}_{\mathrm{I}}\right)$ concentrations. We suggest that the different concentrations of $\mathrm{V}_{\mathrm{O}}$ and $\mathrm{Zn}_{\mathrm{I}}$ are originated from morphological and structural modification. Our results reveal that optical absorption and polarization of $\mathrm{ZnO} \mathrm{NR}$ could be enhanced by producing a high concentration of $\mathrm{V}_{\mathrm{O}}$ and $\mathrm{Zn}_{\mathrm{I}}$. The modification of $\mathrm{V}_{\mathrm{O}}$ and $\mathrm{Zn}_{\mathrm{I}}$ promotes a decrease in the band gap and coexistence of high optical absorption and polarization in our $\mathrm{ZnO} \mathrm{NR}$. Our findings would give a broad insight into the morphological modification and characterization technique on $\mathrm{ZnO} \mathrm{NR}$. The high optical and polarization characteristics of $\mathrm{ZnO} \mathrm{NR}$ are potential for developing the high-performance nanogenerator device for multitype energy harvesting.
\end{abstract}

\section{Introduction}

In recent years, the increase in energy consumption is recorded in the industrial $[1,2]$ and global transportation $[3,4]$ sectors, mainly as a result of increased economic activity and mobility of people across the country. Among the various types of energy, fossil energy shows the greatest number of energy consumption to supply global electricity in the industrial and global transportation [3,5]. The massive exploitation of fossil energy leads to the reduction in a large scale of fossil energy, and it takes a long time to be available again in nature, hundreds to thousands of years. In addition, the consumption of fossil energy is a major cause of environmental problems, such as global warming and air pollution $[6-8]$. Therefore, it is very important to find alternative fossil energy based on electricity from renewable materials, which is safe for the living environment and abundant in nature.
Here, electrical energy can be generated from various resources available in the environment, such as kinetic energy (piezoelectric) $[9,10]$, heat energy (triboelectric) [11-14], and solar energy (photoelectric) [15-17]. In order to increase the number of energy harvesting and efficiency, hybrid nanogenerators have been developed, which can convert multienergy from nature [18-21]. However, the fabrication of a single nanogenerator system that can harvest multitype energy remains a challenge.

Among several materials, which are applied as harvesting energy, zinc oxide $(\mathrm{ZnO})$ received great attention due to its unique properties [22-25]. In addition, $\mathrm{ZnO}$ has been widely used in sensor [26, 27], solar cells [28-30], and spintronics [31-33] applications. $\mathrm{ZnO}$ is a semiconductor material that has a band gap of $\sim 3.3 \mathrm{eV}$ with large excitation binding energy $60 \mathrm{meV}$ and high electron mobility up to $5000 \mathrm{~cm}^{2}$ / Vs [34]. ZnO has high stability at room temperature with 
hexagonal wurtzite structure (No. 186, $P 6_{3} m c$ ) [34]. This structure has a noncentrosymmetric atomic structure, which shows a high polarization $[35,36]$. Here, a small change of displacement can be converted into electrical energy.

In this study, we report on morphological modification and characterization technique on $\mathrm{ZnO} \mathrm{NR}$. Here, the influence of morphological modification on the behavior of optical absorption and polarization of the $\mathrm{ZnO} \mathrm{NR}$ is comprehensively studied by introducing different annealing temperatures. This study will give an important key to develop the high nanogenerator device, which can harvest multitype energy.

\section{Experimental Methods}

The vertically aligned $\mathrm{ZnO} \mathrm{NR}$ on ITO-coated glass substrate have been successfully grown by introducing seed layer on hydrothermal method. The seed layer was prepared from the mixture of zinc acetate dihydrate and ethanol. The seed layer acts as the initial growth for nanorod, which controls the distribution and orientation of $\mathrm{ZnO}$ NR. Firstly, the zinc acetate dihydrate and ethanol were stirred at a temperature of $70^{\circ} \mathrm{C}$ for $45 \mathrm{~min}$ to obtain a homogenous solution. Here, monoethanolamine (MEA) was added to the solution and was stirred at a temperature of $70^{\circ} \mathrm{C}$ for $2 \mathrm{hrs}$ until the solution has a clear and homogenous color. Furthermore, the solution was kept at room temperature for $24 \mathrm{hrs}$. The seed layer was prepared by the solution using a spin coating method. The fabrication of the seed layer was performed for $25 \mathrm{~s}$ with spin that was maintained at $3000 \mathrm{rpm}$. Moreover, preheating at a temperature of $150^{\circ} \mathrm{C}$ for $10 \mathrm{~min}$ and annealing at $550^{\circ} \mathrm{C}$ for $2 \mathrm{hrs}$ were performed.

The $\mathrm{ZnO}$ NR were fabricated by using the $45 \mathrm{mM}$ precursor, a mixture of zinc nitrate tetrahydrate, hexamethylenetetramine (HMT), and deionized water. The hydrothermal process was maintained at a temperature of $90^{\circ} \mathrm{C}$ for $4 \mathrm{hrs}$. Detail of synthesis of $\mathrm{ZnO} \mathrm{NR}$ is presented in Figure 1. Furthermore, the morphological modification was performed by introducing different annealing temperatures. Previously, temperature-dependent morphological modification models have been reported [37]. Here, the morphological modification was categorized in several zones according to $T / T_{\mathrm{m}}$, with $T$ and $T_{\mathrm{m}}$ represent applied annealing temperature and melting point $\left(T_{\mathrm{m}-\mathrm{ZnO}}=1975^{\circ} \mathrm{C}\right)$. In this study, we focused on the three types of $\mathrm{ZnO} \mathrm{NR}$ : without annealing/as-grown $\mathrm{ZnO}$ $\mathrm{NR}$ (ag- $\mathrm{ZnO}$ ) and annealed $\mathrm{ZnO} \mathrm{NR}$ at a temperature of $400^{\circ} \mathrm{C}\left(\mathrm{ZnO} 400^{\circ} \mathrm{C}\right)$ and $500^{\circ} \mathrm{C}\left(\mathrm{ZnO} 500^{\circ} \mathrm{C}\right)$ for $15 \mathrm{~min}$. Both $\mathrm{ZnO} 400^{\circ} \mathrm{C}\left(T / T_{\mathrm{m}}=0.2\right)$ and $\mathrm{ZnO} 500^{\circ} \mathrm{C}\left(T / T_{\mathrm{m}}=0.25\right)$ are included in zone $T$, which has a cone-like structure. In this zone, atoms have low activation energy and imply a low surface diffusion. At the applied annealing temperature, the crystals grow out of the initial nucleation and proceed to the top. Here, the materials have a V-shaped columnar crystal with tapered bottoms and domed tops (cone-like), which are separated by voided boundaries [37].

The morphological modification, including distribution and thickness of $\mathrm{ZnO} \mathrm{NR}$, was studied by surface and crosssectional images using scanning electron microscopy (SEM) FEI: INSPECT S50. The surface density was determined by using a surface density model without any additional characterization instrument (e.g., Brunauer-Emmett-Teller (BET) measurement). Furthermore, photoluminescence (PL) spectra were used to confirm structural modification of the samples. The characteristics of optical absorption and polarization of the $\mathrm{ZnO}$ NR were investigated by spectroscopic ellipsometry Micropack: Spec-EI 2000.

\section{Results and Discussion}

Figure 2 presents the diffraction pattern of the $\mathrm{ZnO}$ NR on ITO-coated glass substrate with different annealing temperatures. A hexagonal wurtzite $\mathrm{ZnO}$ was successfully obtained by the hydrothermal method. Here, the $\mathrm{Zn}(\mathrm{OH})_{2}$ phase (JCPDS No. 00-041-1359) was observed at the diffraction angle of $28^{\circ}$ and $47^{\circ}$ on the ag- $\mathrm{ZnO}$. This result indicates an incomplete conversion of $\mathrm{Zn}(\mathrm{OH})_{2}$ into $\mathrm{ZnO}$. We reveal that annealing leads to the conversion of $\mathrm{Zn}(\mathrm{OH})_{2}$ into $\mathrm{ZnO}$, as indicated by the decrease of $\mathrm{ZnO}(\mathrm{OH})_{2}$ accompanied by the increase of $\mathrm{ZnO}$ peak intensity (JCPDS No. 01-0897102 and 01-075-1533). In addition, the lattice parameter of the $\mathrm{ZnO}$ is obtained by the Rietveld refinement, with the obtained $a=b$ and $c$ value of $3.250 \AA$ and $5.206 \AA$ for ag$\mathrm{ZnO}, 3.249 \AA$ and $5.204 \AA$ for $\mathrm{ZnO} 400^{\circ} \mathrm{C}$, and $3.254 \AA$ and $5.212 \AA$ for $\mathrm{ZnO} 500^{\circ} \mathrm{C}$. Further analysis has been performed to determine the structural modification in the $\mathrm{ZnO} \mathrm{NR}$. Here, grain size $(D)$ and lattice strain $(\varepsilon)$ of the $\mathrm{ZnO} \mathrm{NR}$ are determined by using the Williamson-Hall $(\mathrm{W}-\mathrm{H})$ plot method as follows:

$$
\beta \cos \theta=\frac{K \cdot \lambda}{D}+\varepsilon \sin \theta
$$

with $\beta$ is the full width at half maximum (FWHM) of the diffraction peak, $\theta$ is the diffraction pattern, and $K$ is the constant (0.9). The samples have the grain size of $73.1 \mathrm{~nm}$, $70.8 \mathrm{~nm}$, and $78.3 \mathrm{~nm}$ and the lattice strain of $2.31 \times 10^{-3}$, $1.80 \times 10^{-3}$, and $1.26 \times 10^{-3}$. The decrease of lattice strain indicates that the $\mathrm{ZnO}$ system is towards more stable condition and enhanced crystallinity, which is indicated by the increase of $\mathrm{ZnO}$ peak intensity. This result is consistent with the previous result, where the increase of crystallinity of the $\mathrm{ZnO} \mathrm{NR}$ is attributed to complete conversion $\mathrm{Zn}(\mathrm{OH})_{2}$ into $\mathrm{ZnO}$ assisted by the higher annealing temperature.

Figures 3(a)-3(c) show the morphological modification of the $\mathrm{ZnO} \mathrm{NR}$ on ITO-coated glass substrate. Both of the surface and cross-sectional images provided the representation of distribution and the thickness of the samples. The result shows that the use of a seed layer has successfully generated the vertically aligned as-grown $\mathrm{ZnO}(\mathrm{ag}-\mathrm{ZnO})$, with the thickness of the samples is represented by the length of the nanorod. We found that length and diameter of the $\mathrm{ZnO} \mathrm{NR}$ increase with applying the higher annealing temperature, with the length of $430 \mathrm{~nm}, 1.1 \mu \mathrm{m}$, and $1.4 \mu \mathrm{m}$ and diameter of $139.9 \mathrm{~nm}, 247.3 \mathrm{~nm}$, and $394.0 \mathrm{~nm}$ for the ag- $\mathrm{ZnO}, \mathrm{ZnO} 400^{\circ} \mathrm{C}$ and $\mathrm{ZnO} 500^{\circ} \mathrm{C}$, respectively. In addition, annealing treatment also promotes morphological evolution in $\mathrm{ZnO} \mathrm{NR}$. A cone-like shape was successfully obtained by applying annealing treatment at a temperature 


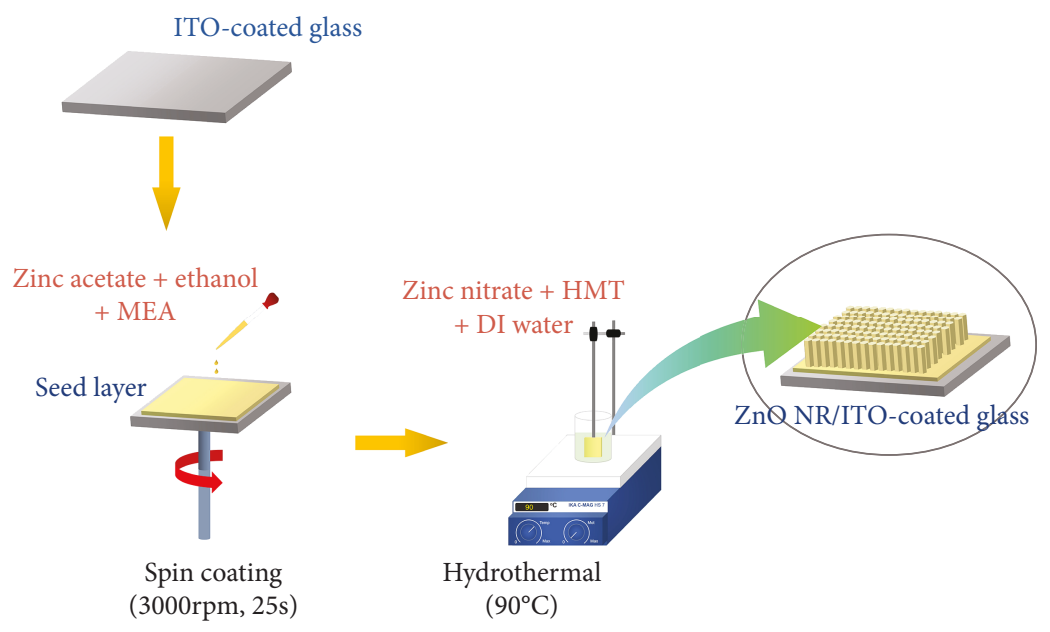

Figure 1: Schematic representation of synthesis of $\mathrm{ZnO}$ NR. A seed layer was firstly prepared by spin coating method using zinc acetate, ethanol, and MEA solution.

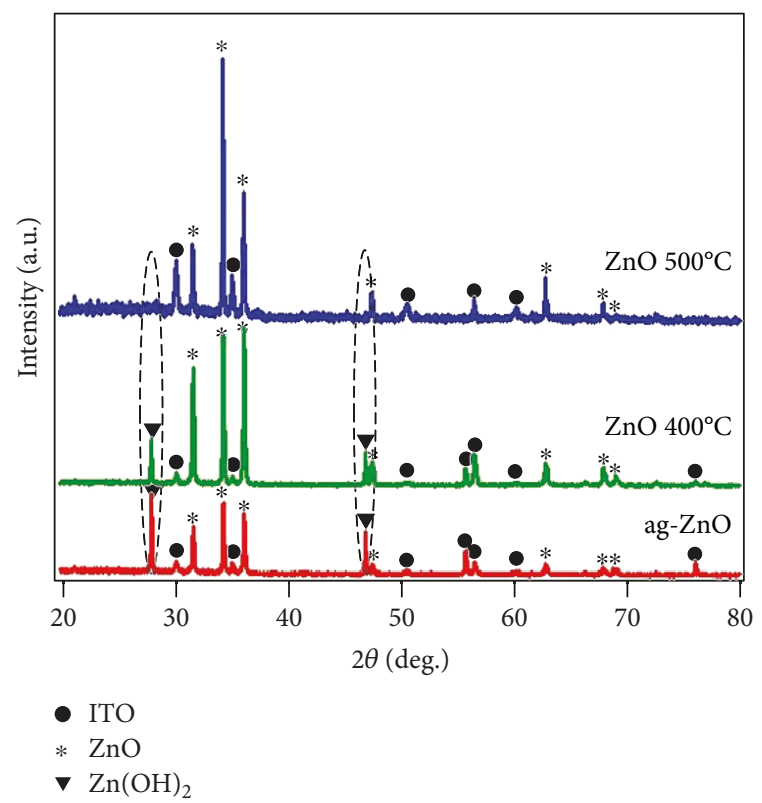

(a)

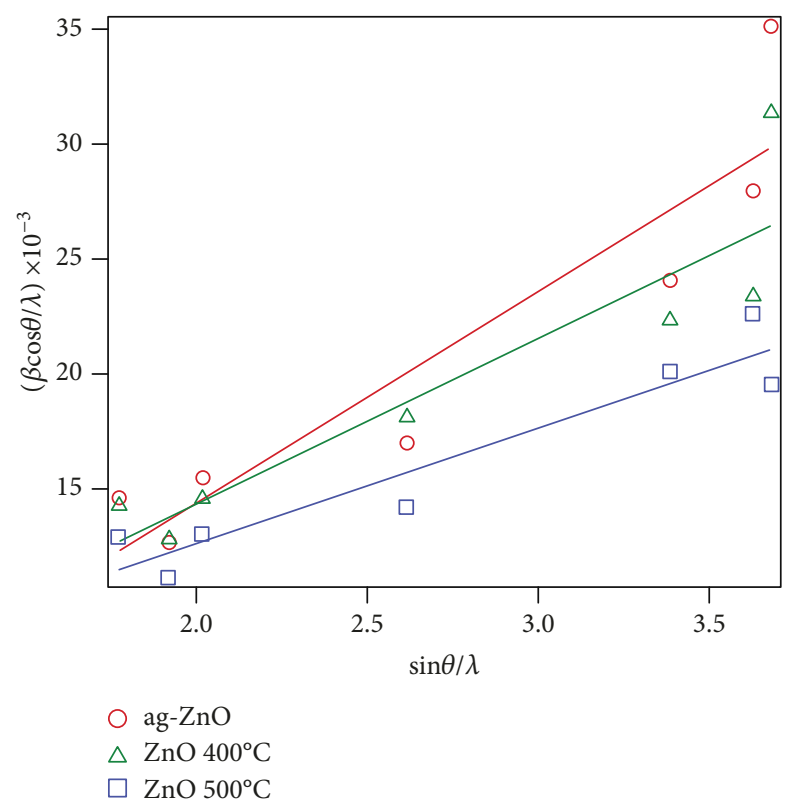

(b)

FIGURE 2: Crystal structure analysis of the $\mathrm{ZnO}$ NR on ITO-coated glass grown by hydrothermal method. (a) Diffraction pattern of the ZnO NR on ITO-coated glass. (b) Structural analysis of the ZnO NR on ITO-coated glass by using Williamson-Hall plot. The observed Zn(OH) phase indicates an incomplete formation of the $\mathrm{ZnO} \mathrm{NR}$.

of $400^{\circ} \mathrm{C}\left(T / T_{\mathrm{m}}=0.2\right)$ and $500^{\circ} \mathrm{C}\left(T / T_{\mathrm{m}}=0.25\right)$. In order to investigate the morphological modification of the samples comprehensively, a surface density calculation has been performed. Here, the surface density is determined by using surface mapping from SEM images without additional characterization instrument.

Figures 3(d)-3(f) represent the surface density model of the samples obtained from SEM images. We found that annealing at $400^{\circ} \mathrm{C}$ is dominated by coarsening of the $\mathrm{ZnO}$ sample. Here, the increase in diameter was accompanied by the decrease of the percentage of surface density from $19.21 \%(\mathrm{ag}-\mathrm{ZnO})$ to become $14.4 \%\left(\mathrm{ZnO} 400^{\circ} \mathrm{C}\right)$. We note that the $\mathrm{ZnO} 500^{\circ} \mathrm{C}$ has the denser surface density than that of the $\mathrm{ZnO} 400^{\circ} \mathrm{C}$, with the percentage of surface density of $17.8 \%$. The increase of both diameter and density indicates the domination of densification during annealing at $500^{\circ} \mathrm{C}$. Material distributions with coarsening and densification process are illustrated in Figure 4. We infer that the variation of density is originated from domination between coarsening and densification. Both coarsening and densification play a role in distribution rearrangement, which decreases (coarsening) or increases (densification) the density of $\mathrm{ZnO} \mathrm{NR}$. In addition, a shape difference of cone-like structure (domed top and tapered bottom sides) provided some void (see Figure 4), which allows light to pass through the $\mathrm{ZnO} \mathrm{NR}$ and subsequently yield high optical absorption in $\mathrm{ZnO} \mathrm{NR}$. 

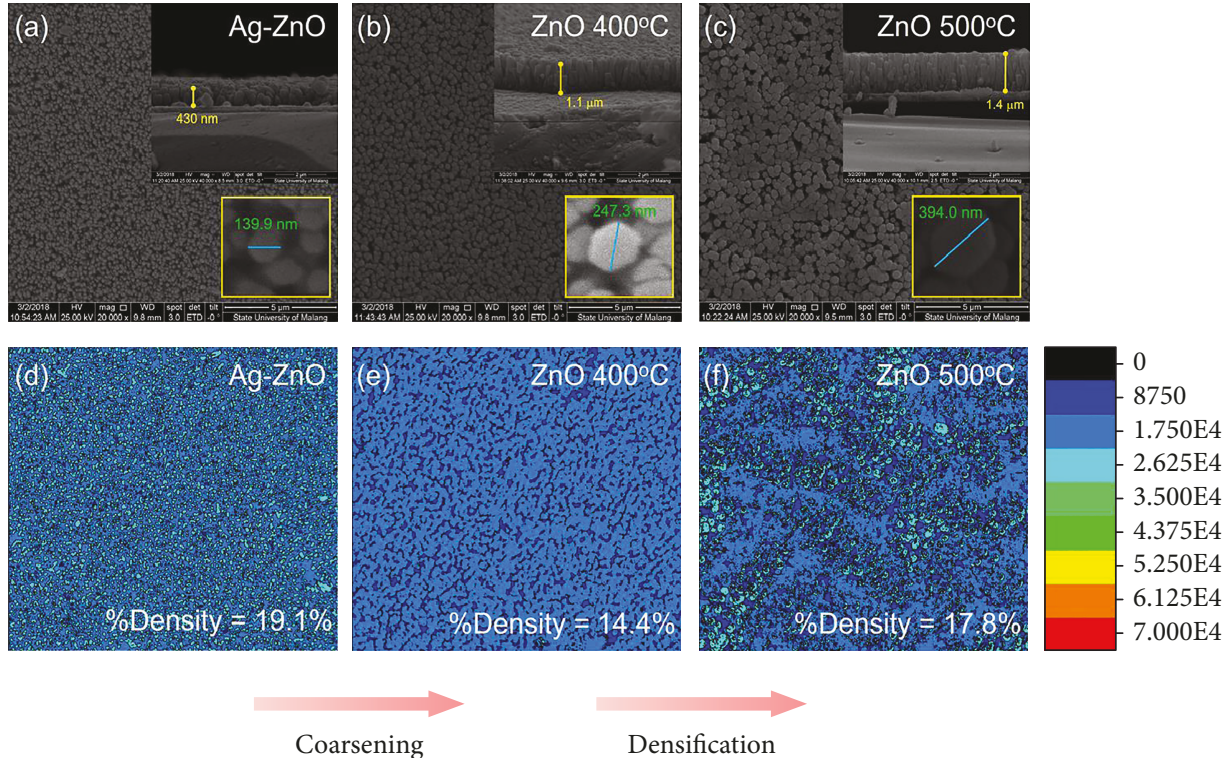

Densification

Figure 3: Morphology of the $\mathrm{ZnO} \mathrm{NR}$ with different annealing temperatures. SEM images of (a) ag- $\mathrm{ZnO}$, (b) $\mathrm{ZnO} 400^{\circ} \mathrm{C}$, and (c) $\mathrm{ZnO} 500^{\circ} \mathrm{C}$ and surface density model of (d) ag- $\mathrm{ZnO}$, (e) $\mathrm{ZnO} 400^{\circ} \mathrm{C}$, and (f) $\mathrm{ZnO} 500^{\circ} \mathrm{C}$.

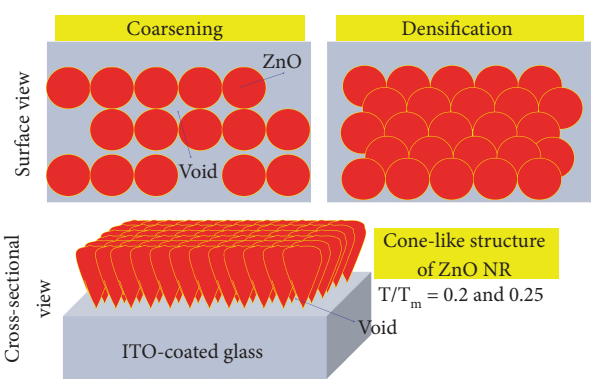

Figure 4: Schematic illustration of distribution of $\mathrm{ZnO}$ NR with domination of coarsening and densification. Cone-like structure of $\mathrm{ZnO} \mathrm{NR}$ provides some void due to shape difference of top and bottom of $\mathrm{ZnO} \mathrm{NR}$.

Furthermore, the optical characterization was performed to investigate the structural modification and optical properties of $\mathrm{ZnO}$ NR. Figure 5 presents PL spectra of the samples analyzed by multiple Gaussian fitting. We noted that the peaks at $2.53 \mathrm{eV}$ and $2.66 \mathrm{eV}$ are originated from the oxygen vacancy $\left(\mathrm{V}_{\mathrm{O}}\right)$. Moreover, the presence of zinc interstitial $\left(\mathrm{Zn}_{\mathrm{I}}\right)$ and near band edge (NBE) is observed at $2.941 \mathrm{eV}$ and $3.15 \mathrm{eV}$. The increase of annealing temperature increases the concentration both of the $\mathrm{V}_{\mathrm{O}}$ and $\mathrm{Zn}_{\mathrm{I}}$. Other studies confirmed that the $V_{O}$ and $Z_{I}$ play an important role in polarization and optical absorption, respectively [36]. Here, the influence of $\mathrm{V}_{\mathrm{O}}$ and $\mathrm{Zn}_{\mathrm{I}}$ on optical absorption and polarization of $\mathrm{ZnO} \mathrm{NR}$ is investigated in detail by spectroscopic ellipsometry.

Figure 6(a) shows the dielectric function of the $\mathrm{ZnO} \mathrm{NR}$ with different annealing temperatures. The result confirms that the increase of temperature promotes the increase in both of real $\left(\varepsilon_{1}\right)$ and imaginary $\left(\varepsilon_{2}\right)$ parts of the dielectric function. Here, the $\varepsilon_{1}$ and $\varepsilon_{2}$ are attributed to dielectric polarization and optical absorption of the system, respectively.

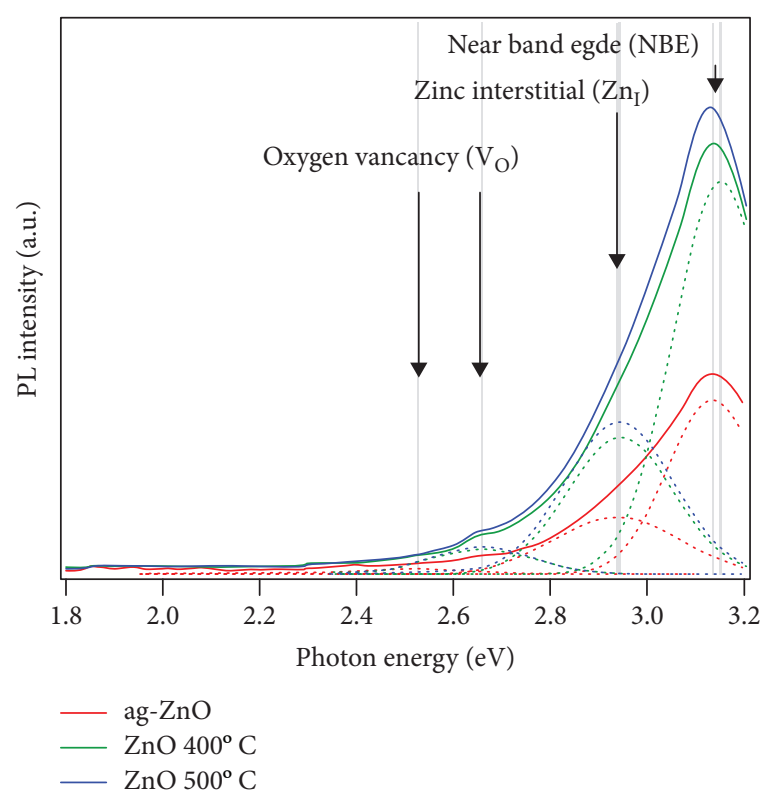

FIgUre 5: Photoluminescence spectra of the $\mathrm{ZnO}$ NR with different annealing temperatures.

The result shows that annealing at $400^{\circ} \mathrm{C}$ promotes the increase of $\varepsilon_{2}$ (with the maximum intensity observed at an energy of $3.21 \mathrm{eV}$ ), while $\varepsilon_{1}$ shows no significant changes. Moreover, the annealing at $500^{\circ} \mathrm{C}$ promotes the increase of both $\varepsilon_{1}$ and $\varepsilon_{2}$. Intriguingly, a sharp peak of the $\varepsilon_{2}$ is also obtained by annealing at a temperature of $500^{\circ} \mathrm{C}$. These results are potentially due to the morphological modification in $\mathrm{ZnO}$ NR. Figure 6(b) represents the illustration of optical absorption and polarization in illuminated $\mathrm{ZnO} \mathrm{NR}$. The electrons excite from valence band (and create a hole) into the conduction band (and excitation state) due to the light 


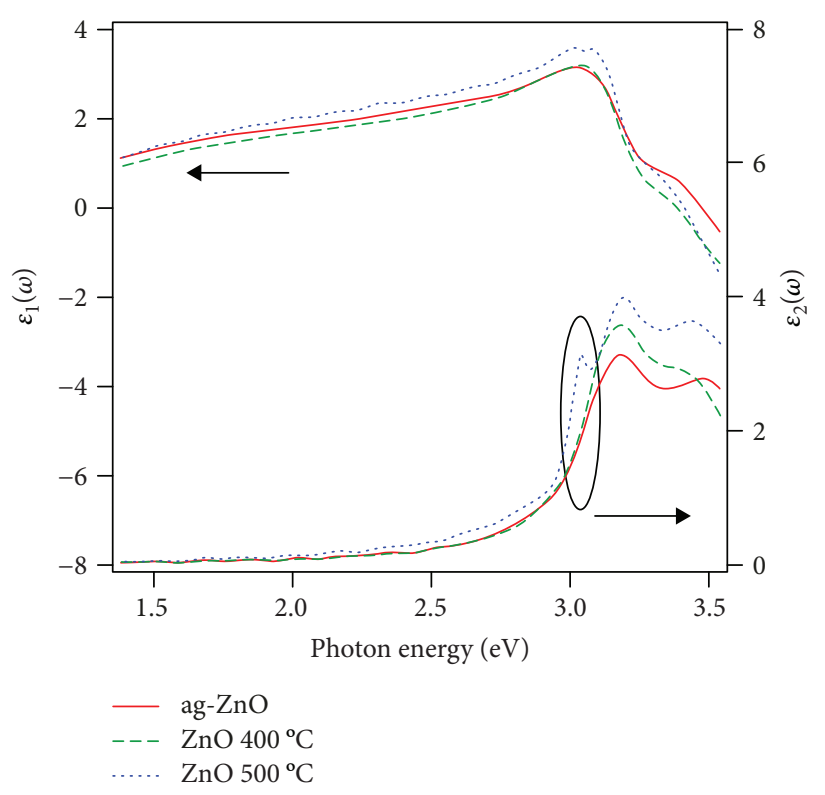

(a)

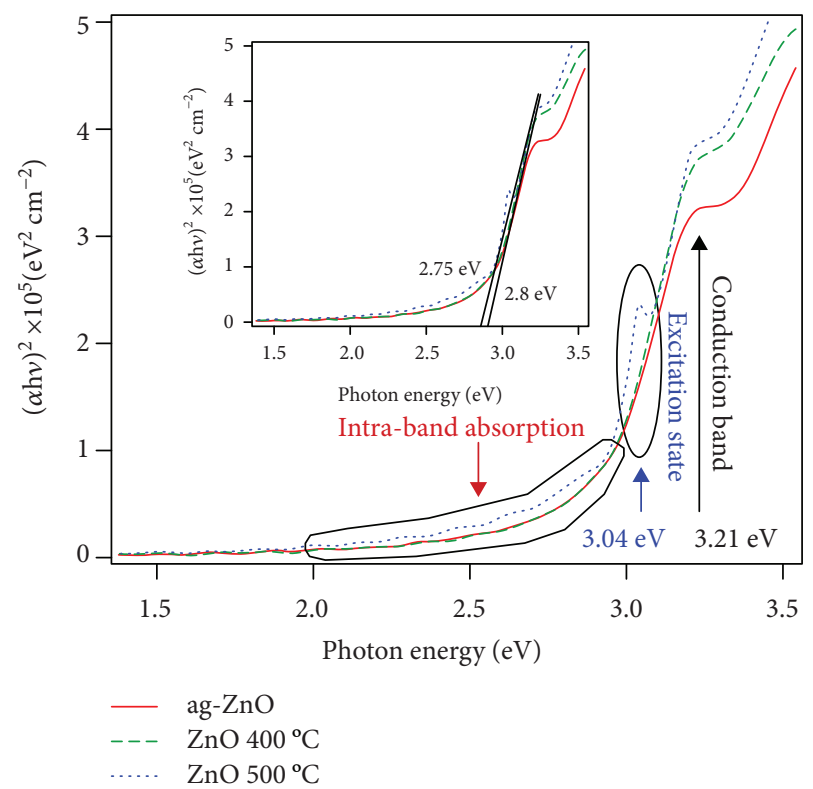

(c)

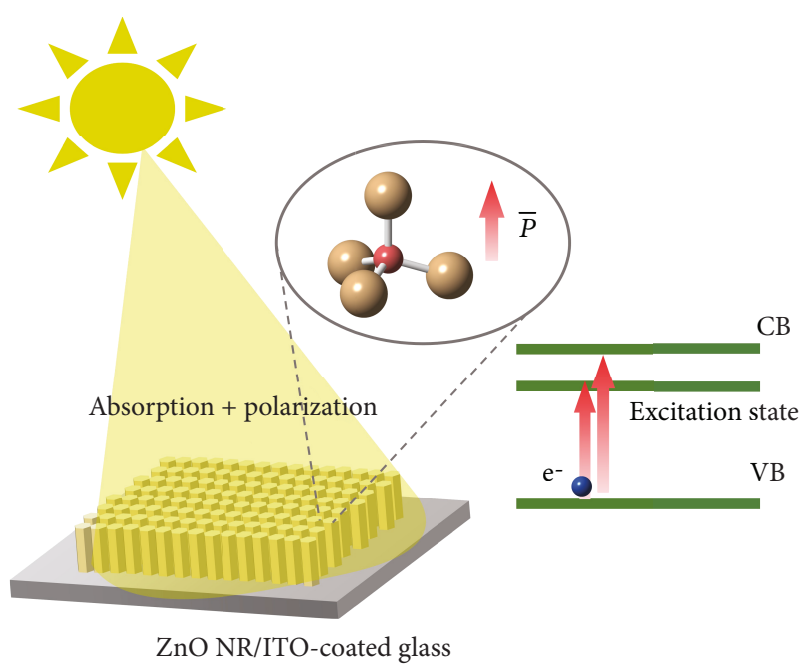

(b)

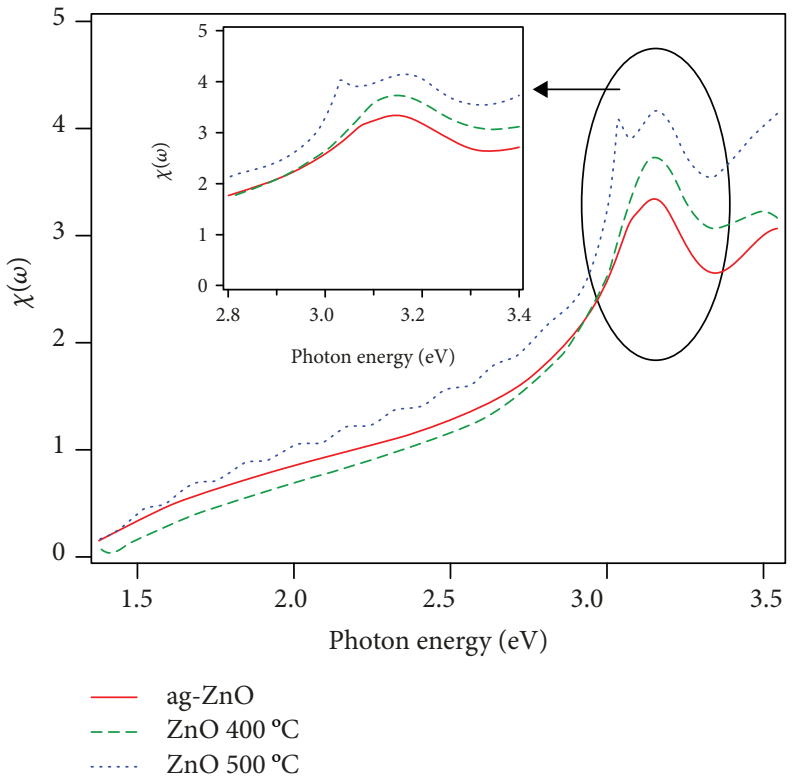

(d)

FIGURE 6: Real and imaginary parts of dielectric function (a), schematic representation of optical absorption and polarization in illuminated $\mathrm{ZnO} \mathrm{NR}$ (b), absorption coefficient (c), and dielectric susceptibility of $\mathrm{ZnO} \mathrm{NR}$ (d). A sharp peak at $3.04 \mathrm{eV}$ indicates the excitation state in $\mathrm{ZnO} 500^{\circ} \mathrm{C}$.

absorption. The excited electron and hole interact with the Coulomb interaction, forming an exciton, and promote the dielectric polarization in the system. Figure 6(c) presents absorption spectra of the $\mathrm{ZnO} \mathrm{NR}$ with different annealing temperatures. The maximum absorption is observed at an energy of $3.21 \mathrm{eV}$, which is indicated conduction band. Moreover, the intraband absorption is observed in the energy range of $2.0-2.5 \mathrm{eV}$, which is presumably due to the contribution of the $\mathrm{V}_{\mathrm{O}}$ in the $\mathrm{ZnO} \mathrm{NR}$. A strong absorption peak, which is related to excitation state, at $3.04 \mathrm{eV}$ is clearly observed on $\mathrm{ZnO} N R 500^{\circ} \mathrm{C}$. This result is potentially due to the double ionization from the high concentration of
$\mathrm{Zn}_{\mathrm{I}}$ in the system. A notable result is confirmed in $\mathrm{ZnO} \mathrm{NR}$ $500^{\circ} \mathrm{C}$, which shows high optical absorption. We infer that the high optical absorption is associated with morphological modification (cone-like structure). In addition, the ag- $\mathrm{ZnO}$ and $\mathrm{ZnO} 400^{\circ} \mathrm{C}$ show the same band gap of $\sim 2.8 \mathrm{eV}$, while the $\mathrm{ZnO} 500^{\circ} \mathrm{C}$ show the decrease in the band gap of $\sim 2.75 \mathrm{eV}$. A plausible explanation of these characteristics is due to the existence of the $V_{O}$ and $Z_{I}$ excitation state, which further provides the wider energy range absorption of light. Previously, low band gap $\mathrm{ZnO}$ was reported in other studies, where optical absorption of the $\mathrm{ZnO}$ is presented [38]. The decrease of band gap was promoted by the presence of the 


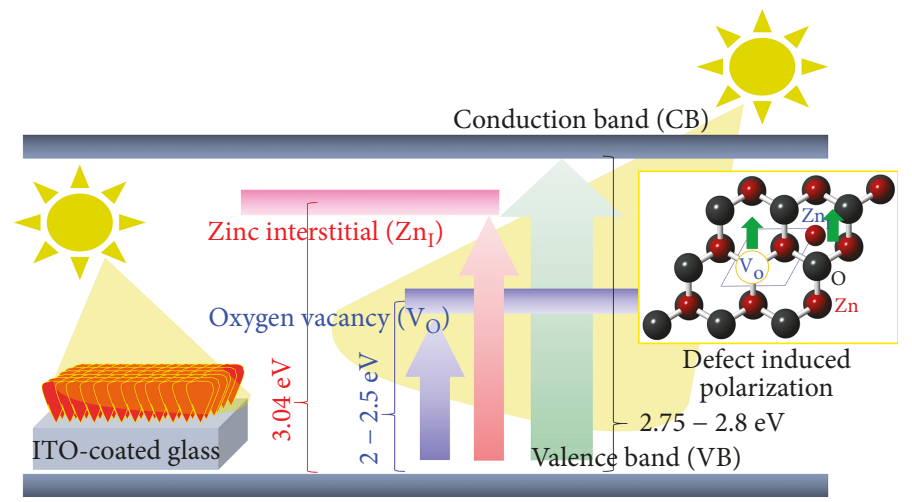

Figure 7: Schematic diagram of the influence of $\mathrm{V}_{\mathrm{O}}$ and $\mathrm{Zn}_{\mathrm{I}}$ on optical absorption and polarization of $\mathrm{ZnO}$ NR. The existence of both $\mathrm{V}_{\mathrm{O}}$ and $\mathrm{Zn}_{\mathrm{I}}$ promoted large number of optical absorption and polarizability of the $\mathrm{ZnO} \mathrm{NR}$ during light illumination.

midgap state in doped $\mathrm{ZnO}$ system $[38,39]$. In this study, the presence of the midgap state in our system is mainly associated with the existence of the $\mathrm{V}_{\mathrm{O}}$ and $\mathrm{Zn}_{\mathrm{I}}$ excitation state.

The next analysis is focused on the investigation of the polarization of the $\mathrm{ZnO} \mathrm{NR}$. The polarization response of the system can be indicated by its susceptibility $(\chi)$ value. Here, the dielectric susceptibility is obtained from a dielectric function of the $\mathrm{ZnO} \mathrm{NR}$ by the following relation [35].

$$
\begin{aligned}
& \chi(\omega)=\chi^{\prime}(\omega)+\chi^{\prime \prime}(\omega), \\
& \chi(\omega)=\left[\varepsilon_{1}(\omega)-1\right]-i \varepsilon_{2}(\omega),
\end{aligned}
$$

with $\chi^{\prime}(\omega)$ and $\chi^{\prime \prime}(\omega)$ are the real part and imaginary part of dielectric susceptibility. Figure $6(\mathrm{~d})$ confirms that the dielectric susceptibility of the $\mathrm{ZnO} \mathrm{NR}$ increases for the higher photon energy in the range of $1.4-3.0 \mathrm{eV}$ and increases significantly at a photon energy of $3.21 \mathrm{eV}$. Moreover, the same profile is also observed in dielectric susceptibility. The new excitation state promotes a sharp dielectric susceptibility at an energy of $3.04 \mathrm{eV}$ on $\mathrm{ZnO} 500^{\circ} \mathrm{C}$, promoting a wide dielectric susceptibility at energy $3.04-3.21 \mathrm{eV}$ as presented by the blue dashed line in inset of Figure 6(d). The higher and wider dielectric susceptibility provide evidence of the enhancement of polarization in the $\mathrm{ZnO} \mathrm{NR}$. The mechanism of optical absorption and polarization of the sample is illustrated in Figure 7 . The presence of the $\mathrm{V}_{\mathrm{O}}$ and $\mathrm{Zn}_{\mathrm{I}}$ potentially reduce the binding of the system and further promote high polarizability. Moreover, it allows the high polarizability. These results show that the increase of $\mathrm{Zn}_{\mathrm{I}}$ and $\mathrm{V}_{\mathrm{O}}$ concentration in the $\mathrm{ZnO} \mathrm{NR}$ has successfully enhanced their optical absorption and dielectric susceptibility.

\section{Conclusions}

The structure and morphology of the $\mathrm{ZnO}$ NR have been successfully modified by introducing different annealing temperatures. The increase of annealing temperature promoted the complete formation of the $\mathrm{ZnO}$ phase and the increase of the ZnO NR crystallinity with the more stable condition, as indicated by decreasing in lattice strain. The length and diameter increase with a respective value up to $1.4 \mu \mathrm{m}$ and
$394.0 \mathrm{~nm}$ for the annealing at $500^{\circ} \mathrm{C}$. Moreover, the change of surface density and increase of oxygen vacancy $\left(\mathrm{V}_{\mathrm{O}}\right)$ and zinc interstitial $\left(\mathrm{Zn}_{\mathrm{I}}\right)$ concentrations of the $\mathrm{ZnO} \mathrm{NR}$ were observed at the higher annealing temperature. The optical analysis revealed that the presence of high $\mathrm{Zn}_{\mathrm{I}}$ and $\mathrm{V}_{\mathrm{O}}$ concentration changed the band gap from 2.8 to become $2.75 \mathrm{eV}$ and promoted the increase of optical absorption and polarization of the $\mathrm{ZnO} \mathrm{NR}$, respectively. Interestingly, the high concentration also created the new excitation state, which enhanced both optical absorption and polarization of the $\mathrm{ZnO} \mathrm{NR}$. The coexistence of high optical absorption and polarization will provide a favorable condition which is essential to design $\mathrm{ZnO}$ NR-based multitype energy nanogenerators.

\section{Data Availability}

The data used to support the findings of this study are available from the corresponding author upon request.

\section{Conflicts of Interest}

The authors declare that there is no conflict of interest regarding the publication of this paper.

\section{Acknowledgments}

The authors gratefully acknowledge DRPM, Ministry of Research, Technology and Higher Education (RISTEKDIKTI) of the Republic of Indonesia for the financial support of PBK grant.

\section{References}

[1] A. Otsuka, "Demand for industrial and commercial electricity: evidence from Japan," Journal of Economic Structures, vol. 4, no. 1, p. 9, 2015.

[2] A. Soepardi, P. Pratikto, P. Santoso, I. Tama, and P. Thollander, "Linking of barriers to energy efficiency improvement in Indonesia's steel industry," Energies, vol. 11, no. 1, p. 234, 2018.

[3] M. Song, N. Wu, and K. Wu, "Energy consumption and energy efficiency of the transportation sector in Shanghai," Sustainability, vol. 6, no. 2, pp. 702-717, 2014. 
[4] M. Figueroa, O. Lah, L. M. Fulton, A. McKinnon, and G. Tiwari, "Energy for transport," Annual Review of Environment and Resources, vol. 39, no. 1, pp. 295-325, 2014.

[5] M. Jorli, S. van Passel, and H. Sadeghi Saghdel, "External costs from fossil electricity generation: a review of the applied impact pathway approach," Energy \& Environmental Science, vol. 29, no. 5, pp. 635-648, 2018.

[6] M. Z. Jacobson, "Review of solutions to global warming, air pollution, and energy security," Energy and Environmental Science, vol. 2, no. 2, pp. 148-173, 2009.

[7] B. K. Bose, "Global warming: energy, environmental pollution, and the impact of power electronics," IEEE Industrial Electronics Magazine, vol. 4, no. 1, pp. 6-17, 2010.

[8] F. Perera, "Pollution from fossil-fuel combustion is the leading environmental threat to global pediatric health and equity: solutions exist," International Journal of Environmental Research and Public Health, vol. 15, no. 1, p. 16, 2018.

[9] C. Xue, J. Li, Q. Zhang et al., "A novel arch-shape nanogenerator based on piezoelectric and triboelectric mechanism for mechanical energy harvesting," Nanomaterials, vol. 5, no. 1, pp. 36-46, 2015.

[10] S.-H. Baek and I.-K. Park, "Flexible piezoelectric nanogenerators based on a transferred $\mathrm{ZnO}$ nanorod/Si micro-pillar array," Nanotechnology, vol. 28, no. 9, article 095401, 2017.

[11] J. Chun, B. U. Ye, J. W. Lee et al., "Boosted output performance of triboelectric nanogenerator via electric double layer effect," Nature Communications, vol. 7, article 12985, 2016.

[12] L. Dhakar, S. Gudla, X. Shan et al., "Large scale triboelectric nanogenerator and self-powered pressure sensor array using low cost roll-to-roll UV embossing," Scientific Reports, vol. 6, no. $1,2016$.

[13] J. Wang, C. Wu, Y. Dai et al., "Achieving ultrahigh triboelectric charge density for efficient energy harvesting," Nature Communications, vol. 8, no. 1, p. 88, 2017.

[14] Y. Wang, Y. Yang, and Z. L. Wang, "Triboelectric nanogenerators as flexible power sources," npj Flexible Electronics, vol. 1, no. 1, p. 10, 2017.

[15] A. Kathalingam, S. Valanarasu, V. Senthilkumar, and J.-K. Rhee, "Piezo and photoelectric coupled nanogenerator using CdSe quantum dots incorporated $\mathrm{ZnO}$ nanowires in ITO/ZnO NW/Si structure," Materials Chemistry and Physics, vol. 138, no. 1, pp. 262-269, 2013.

[16] J. Lee, S. R. A. Raza, P. J. Jeon, J. S. Kim, and S. Im, “Deep blue energy harvest photovoltaic switching by heptazole-based organic Schottky diode circuits," NPG Asia Materials, vol. 8, no. 6, p. e278, 2016.

[17] K.-T. Lee, J.-Y. Jang, J. Zhang, S.-M. Yang, S. Park, and H. J. Park, "Highly efficient colored perovskite solar cells integrated with ultrathin subwavelength plasmonic nanoresonators," Scientific Reports, vol. 7, no. 1, p. 10640, 2017.

[18] D.-Y. Lee, H. Kim, H.-M. Li et al., "Hybrid energy harvester based on nanopillar solar cells and PVDF nanogenerator," Nanotechnology, vol. 24, no. 17, article 175402, 2013.

[19] X. Wang, B. Yang, J. Liu, Y. Zhu, C. Yang, and Q. He, “A flexible triboelectric-piezoelectric hybrid nanogenerator based on $\mathrm{P}(\mathrm{VDF}-\mathrm{TrFE})$ nanofibers and PDMS/MWCNT for wearable devices," Scientific Reports, vol. 6, no. 1, article 36409, 2016.

[20] M.-K. Kim, M. S. Kim, S. E. Jo, and Y. J. Kim, “Triboelectricthermoelectric hybrid nanogenerator for harvesting frictional energy," Smart Materials and Structures, vol. 25, no. 12, article 125007, 2016.
[21] H. Li, L. Su, S. Kuang et al., "Multilayered flexible nanocomposite for hybrid nanogenerator enabled by conjunction of piezoelectricity and triboelectricity," Nano Research, vol. 10, no. 3, pp. 785-793, 2017.

[22] M. S. Akhtar, J. H. Hyung, O. B. Yang, N. K. Cho, H. I. Hwang, and S. K. Lee, "Thermally grown $\mathrm{ZnO}$ nanosheets for high efficiency dye-sensitized solar cells," Journal of Nanoscience and Nanotechnology, vol. 10, no. 5, pp. 3654-3658, 2010.

[23] M. Wanit, J. Yeo, S. J. Hong et al., "ZnO nano-tree growth study for high efficiency solar cell,” Energy Procedia, vol. 14, pp. 1093-1098, 2012.

[24] X. Li, J. Song, S. Feng et al., "High-efficiency piezoelectric micro harvester for collecting low-frequency mechanical energy," Nanotechnology, vol. 27, no. 48, article 485402, 2016.

[25] M. Giannouli, K. Govatsi, G. Syrrokostas, S. Yannopoulos, and G. Leftheriotis, "Factors affecting the power conversion efficiency in ZnO DSSCs: nanowire vs. nanoparticles," Materials, vol. 11, no. 3, p. 411, 2018.

[26] L. Zhu and W. Zeng, "Room-temperature gas sensing of ZnObased gas sensor: a review," Sensors and Actuators A: Physical, vol. 267, pp. 242-261, 2017.

[27] T. Park, K. E. Lee, N. Kim, Y. Oh, J.-K. Yoo, and M.-K. Um, "Aspect ratio-controlled $\mathrm{ZnO}$ nanorods for highly sensitive wireless ultraviolet sensor applications," Journal of Materials Chemistry C, vol. 5, no. 46, pp. 12256-12263, 2017.

[28] L. Loh and S. Dunn, "Recent progress in ZnO-based nanostructured ceramics in solar cell applications," Journal of Nanoscience and Nanotechnology, vol. 12, no. 11, pp. 82158230, 2012.

[29] Z.-L. Tseng, C.-H. Chiang, and C.-G. Wu, "Surface engineering of $\mathrm{ZnO}$ thin film for high efficiency planar perovskite solar cells," Scientific Reports, vol. 5, no. 1, 2015.

[30] A. Gholizadeh, A. Reyhani, P. Parvin, S. Z. Mortazavi, and M. Mehrabi, "Enhancement of Si solar cell efficiency using $\mathrm{ZnO}$ nanowires with various diameters," Materials Research Express, vol. 5, no. 1, article 015040, 2018.

[31] F. Pan, C. Song, X. J. Liu, Y. C. Yang, and F. Zeng, "Ferromagnetism and possible application in spintronics of transitionmetal-doped $\mathrm{ZnO}$ films," Materials Science and Engineering: R: Reports, vol. 62, no. 1, pp. 1-35, 2008.

[32] Z. Dai, A. Nurbawono, A. Zhang et al., "C-doped ZnO nanowires: electronic structures, magnetic properties, and a possible spintronic device," The Journal of Chemical Physics, vol. 134, no. 10, article 104706, 2011.

[33] R. V. Hariwal, H. K. Malik, A. Negi, and A. Kandasami, "Controlling room temperature ferromagnetism and band gap in $\mathrm{ZnO}$ nanostructured thin films by varying angle of implantation," RSC Advances, vol. 8, no. 12, pp. 6278-6287, 2018.

[34] C. Klingshirn, "ZnO: material, physics and applications," Chemphyschem, vol. 8, no. 6, pp. 782-803, 2007.

[35] R. Kurniawan, I. M. Sutjahja, T. Winata et al., "Polarization behavior of zinc oxide thin films studied by temperature dependent spectroscopic ellipsometry," Optical Materials Express, vol. 7, no. 11, pp. 3902-3908, 2017.

[36] R. Kurniawan, F. Willy, E. Nurfani et al., "Illumination effects on the ferroelectric properties of zinc oxide films grown by DC-unbalanced magnetron sputtering," Materials Research Express, vol. 4, no. 2, article 024003, 2017.

[37] P. B. Barna and M. Adamik, "Fundamental structure forming phenomena of polycrystalline films and the structure zone models," Thin Solid Films, vol. 317, no. 1-2, pp. 27-33, 1998. 
[38] X. Jiang, Q. Lin, M. Zhang, G. He, and Z. Sun, "Microstructure, optical properties, and catalytic performance of $\mathrm{Cu}_{2} \mathrm{O}$-modified $\mathrm{ZnO}$ nanorods prepared by electrodeposition," Nanoscale Research Letters, vol. 10, no. 1, p. 30, 2015.

[39] Y. Darma, C. D. Satrya, R. Marlina et al., "Plasmon-exciton interaction and screening of exciton in $\mathrm{ZnO}$-based thin film on bulk Pt as analyzed by spectroscopic ellipsometry," Japanese Journal of Applied Physics, vol. 56, no. 1S, article 01AD06, 2017. 

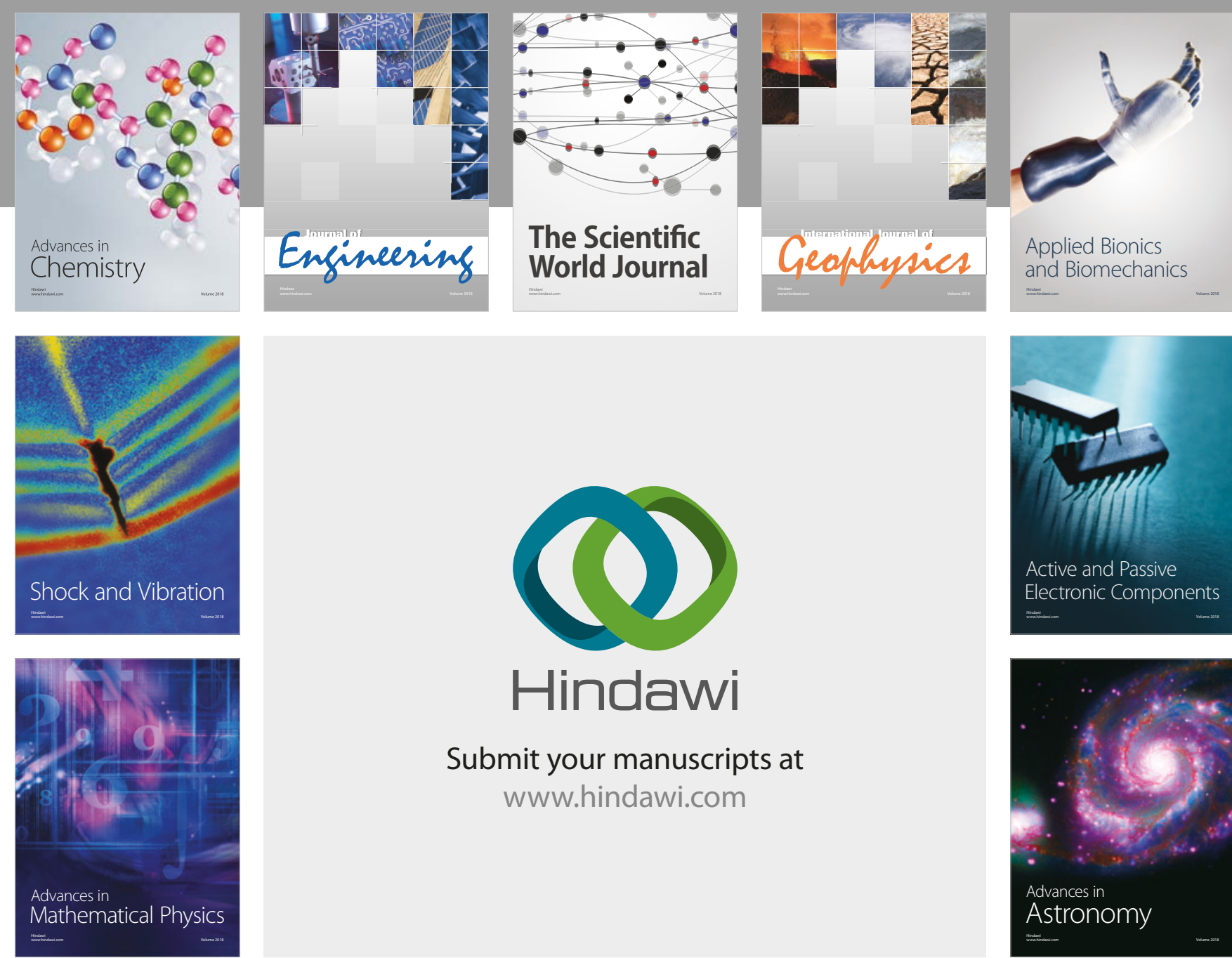

Submit your manuscripts at

www.hindawi.com

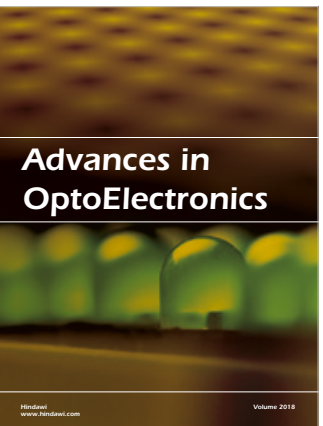

\section{Rotcting Machinery}
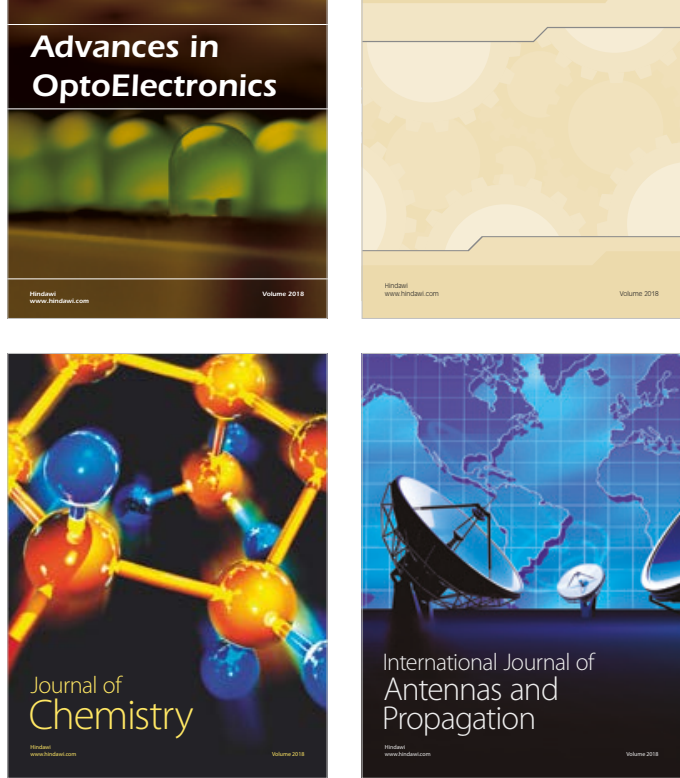

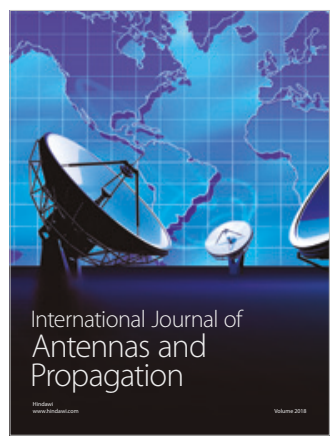

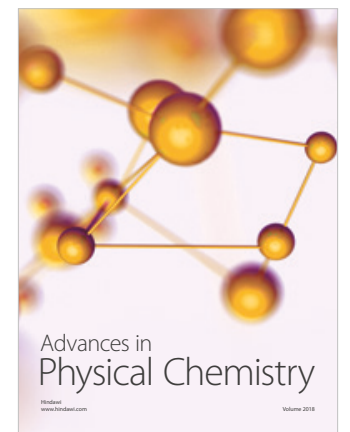

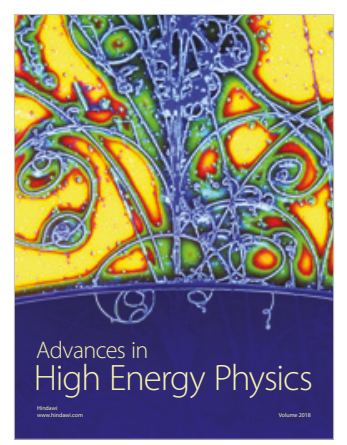

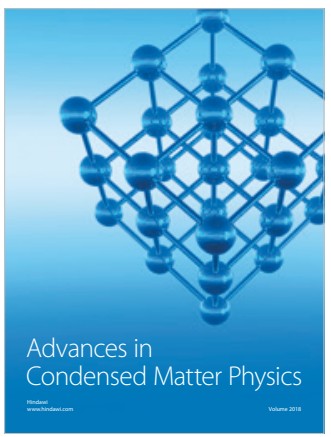

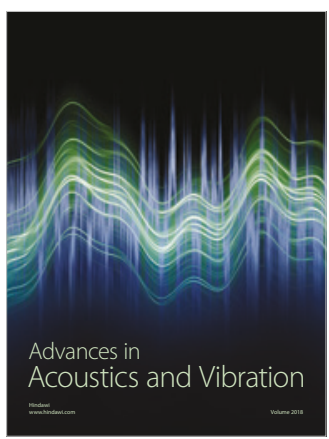

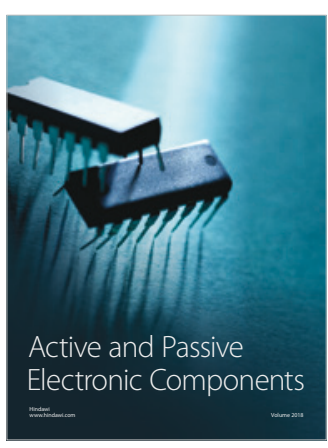
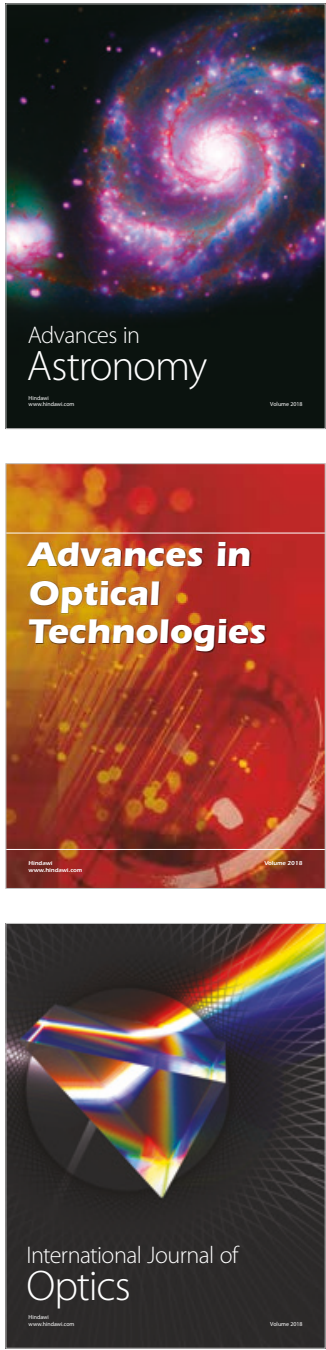